\title{
Telehealth Adoption and Discontinuation by US Hospitals: Results From 2 Quasi-Natural Experiments
}

\author{
Aaron Baird ${ }^{1,2}$, MBA, PhD; Yichen Cheng ${ }^{3}$, PhD; Yusen Xia ${ }^{3}$, MS, PhD \\ ${ }^{1}$ Institute of Health Administration, Georgia State University, Atlanta, GA, United States \\ ${ }^{2}$ Department of Computer Information Systems, Robinson College of Business, Georgia State University, Atlanta, GA, United States \\ ${ }^{3}$ Institute for Insight, Robinson College of Business, Georgia State University, Atlanta, GA, United States
}

\section{Corresponding Author:}

Aaron Baird, MBA, PhD

Institute of Health Administration

Georgia State University

35 Broad Street

Suite 805

Atlanta, GA, 30303-3083

United States

Phone: 14044137639

Fax: 14044137639

Email: abaird@gsu.edu

\section{Abstract}

Background: Prior US hospital telehealth (video visit) studies have focused on describing factors that influence telehealth adoption or performance effects for specific patient segments, hospital systems, or geographic regions. To our knowledge, a larger-scale, national-level (US) study has yet to be conducted on the causal impacts of hospital telehealth adoption as well as discontinuation.

Objective: The aim of this study is to understand the causal impact of US hospital telehealth adoption or discontinuation on hospital performance from 2016 to 2018.

Methods: We analyzed impacts of telehealth adoption or discontinuation by US hospitals on emergency department visits, total ambulatory visits (minus emergency department visits), outpatient services revenue, total facility expenses, and total hospital revenue for the 2016-2018 period. We specifically focused on performance effects for hospitals that switched from not having telehealth to adopting telehealth, or vice versa, during the 2016-2018 period, thus exploiting 2 quasi-natural experiments. We applied a difference-in-differences research design to each of the 2 main analyses. We compared hospitals that have made a telehealth change to groups of hospitals with similar characteristics that did not make a telehealth change, which established a counterfactual. To appropriately match hospitals between treatment and control groups, we applied propensity score matching. Our primary data were from the American Hospital Association Annual Survey and the Healthcare Cost Report Information System data. Several control variables were obtained from additional sources, including the Area Health Resource File and the Federal Communications Commission.

Results: We found that telehealth adoption by US hospitals during the 2016-2018 period resulted in, on average, an increased number of total ambulatory visits $(P=.008)$, increased total facility expenses $(P<.001)$, and increased hospital revenue $(P=.004)$ compared with the control group. We found that telehealth discontinuation during the same period resulted in, on average, decreased outpatient services revenue $(P=.02)$ compared with the control group.

Conclusions: Our findings suggest that telehealth adoption increases use but has mixed impacts on performance, given that cost and revenue increase. However, once telehealth is offered, removing it can have a negative impact on performance, implying that returning to prior performance levels, if telehealth is removed, may be challenging.

(JMIR Form Res 2022;6(2):e28979) doi: 10.2196/28979

\section{KEYWORDS}

telehealth; hospitals; adoption; discontinuation; health information system 


\section{Introduction}

\section{Background}

Telehealth, in the form of video visits between health care providers and patients (telehealth, henceforth), is used by hospitals and their affiliated clinics to maintain or improve access to postdischarge follow-up, continuity of care, and care for nonurgent issues [1-5]. Although a number of studies have evaluated the impacts of telehealth on outcomes [2,6-10], such studies have primarily focused on either the determinants of telehealth adoption [11] or effects of telehealth primarily for patient populations limited to specific hospital systems or regions [4,12-14]. Larger-scale studies exploiting national-level natural variation in telehealth adoption as well as discontinuation over multiple years have yet to be conducted.

Overall, although many view telehealth with optimism, we do not yet fully understand the impact on hospital-level outcomes when telehealth is adopted or, in the case of challenges, discontinued. Thus, this study seeks to understand such impacts, including impacts resulting from telehealth discontinuation, which is not an aspect of telehealth that has been considered yet in the literature. For instance, in regard to challenges that may lead to discontinuation of telehealth, it is well known that telehealth can be especially difficult to sustain and integrate with workflows designed for in-person interactions [7] and can result in variable outcomes $[15,16]$. Particular challenges for hospitals offering telehealth include prioritization of the success of telehealth; engagement by providers, patients, and leaders; and continuous improvement [17]. Many times, telehealth is initially viewed with optimism, but the reality is that many clinicians have stopped using it in the past after a few visits [17]. Especially important to mitigate such issues are deliberate efforts to create protocols, develop appropriate scheduling techniques, and formalize an understanding for when telehealth is and is not appropriate [18], which, if not addressed, can lead to significant challenges, resistance, or program failure. Furthermore, the effects of telehealth have been found to have mixed or even positive effects on costs $[3,19]$. In the case of telehealth substituting for expensive in-person visits such as visits to the emergency department (ED) or in-patient admissions, telehealth can be cost-effective [20,21]. However, when offering video-based consultations to patients, it is also possible that increased access to health care increases provider costs and the number of visits requested by patients, which can result in less revenue, especially if telehealth is reimbursed at a lower rate than in-person visits [3].

Finally, telehealth is a particularly interesting case because it can be technically relatively easy to adopt or discontinue, especially if using a vendor-supported or cloud-based system, but, as discussed previously, can simultaneously result in significant and costly workflow challenges $[8,22]$. It is well known that telehealth use is an excellent opportunity to enhance access to care, but it is also well known that inadequate barrier identification and management can doom telehealth pilots $[17,23]$. Furthermore, given the variety of factors that may influence telehealth adoption, use, and potential discontinuation, several factors, including hospital and regional characteristics, must be controlled for. Thus, this study comprehensively examines both telehealth adoption and discontinuation in the United States from 2016 to 2018 through analysis of 2 quasi-natural experiments (ie, one for adoption and one for discontinuation), while controlling for several potential confounding variables. We also conduct robustness checks to validate our findings.

\section{Implications}

Our primary findings are as follows: (1) telehealth adoption by US hospitals during the period studied resulted in increased ambulatory visits, increased facility expenses, and increased hospital revenue in comparison with the control group, and (2) telehealth discontinuation resulted in decreased outpatient services revenue in comparison with the control group. The implications are that adopting telehealth increases use of ambulatory services, which implies greater access, but these findings also suggest that profit performance will likely be mixed. Furthermore, removing telehealth once offered can negatively affect future performance, implying that performance levels likely will not simply return to what they were before telehealth was adopted and then subsequently discontinued. Further implications are discussed later.

\section{Methods}

\section{Overview}

To address our research objectives, we analyzed the impact of telehealth adoption or discontinuation by US hospitals from 2016 to 2018 using difference-in-differences estimation of 2 quasi-natural experiments: (1) US hospital telehealth adoption during the period considered and (2) US hospital telehealth discontinuation during the same period. We specifically considered impacts of telehealth adoption or discontinuation during this period on ED visits, total ambulatory visits (minus ED visits), outpatient services revenue, total facility expenses, and hospital revenue (a more detailed description of these dependent variables is available in Multimedia Appendix 1).

\section{Data}

Data on which US hospitals continued to offer, or discontinued, telehealth were obtained from the American Hospital Association (AHA) Annual Survey for 2016-2018 (although data quality may be a concern, prior studies such as the one by Adler-Milstein et al [11] have found the AHA data to be highly consistent with the data from the Healthcare Information and Management Systems Society data set, suggesting high data quality). Outcome data for ED visits, total ambulatory visits, outpatient services revenue, total facility expenses, and hospital revenue per US hospital were obtained from the 2016-2018 AHA Annual Survey and the AHA's Centers for Medicare \& Medicaid Services Healthcare Cost Report Information System (HCRIS) data (ie, AHA's version of the Centers for Medicare \& Medicaid Services HCRIS data). Covariates used for propensity score matching and controls were obtained from the AHA data sets and from the US county-level data available from the Area Health Resource File, as well as the Area Deprivation Index (ADI) sourced from BroadStreet, health rankings data from the University of Wisconsin Population 
Health Institute, and supplementary data from the Federal for rival explanations. Controls and covariates were derived Communications Commission for broadband speeds per county. from a literature review [24-30]. Tables 1 and 2 describe the We included several controls from these data sources to account relevant variables. 
Table 1. Telehealth adoption sample descriptive statistics averaged for 2016-2018 (for 135 US hospitals that did not have telehealth for all 3 years or started to adopt telehealth in 2017 or 2018).

\begin{tabular}{|c|c|c|c|}
\hline Group and variable & Description & Value, $\mathrm{N}$ & Values, mean (SD; range) \\
\hline \multicolumn{4}{|l|}{ Telehealth adoption and outcomes } \\
\hline Telehealth video-based consultation & $\begin{array}{l}\text { Whether a hospital adopted tele- } \\
\text { health in a given year }\end{array}$ & 405 & $0.39(0.49 ; 0-1)$ \\
\hline EDVisits $^{\mathrm{a}}$ (in thousands) & $\begin{array}{l}\text { Number of emergency department } \\
\text { visits }\end{array}$ & 405 & $47.02(32.98 ; 0-174.96)$ \\
\hline TotAmbVisits $^{\mathrm{a}}$ (in thousands) & $\begin{array}{l}\text { Total number of ambulatory visits } \\
\text { (minus emergency department vis- } \\
\text { its) }\end{array}$ & 405 & $196(209.36 ; 2.09-1488.13)$ \\
\hline OutpatSerRev $^{\mathrm{a}}$ (in millions, US \$) & Outpatient services revenue & 393 & $179(312.35 ; 0-2831.15)$ \\
\hline TotFacExp ${ }^{\mathrm{a}}$ (in millions, US \$) & Total facility expenses & 405 & $\begin{array}{l}321.61(342.3 ; 18.97- \\
2687.47)\end{array}$ \\
\hline HospRev $^{\mathrm{a}}$ (in millions, US \$) & Total hospital revenue & 393 & $152.34(283.84 ; 0-2399.62)$ \\
\hline \multicolumn{4}{|l|}{ Hospital-level variables } \\
\hline SystemOwned & System ownership & 405 & $0.71(0.45 ; 0-1)$ \\
\hline WageIndx & $\begin{array}{l}\text { Index of hospital labor market } \\
\text { wages }\end{array}$ & 393 & $1.01(0.15 ; 0.72-1.35)$ \\
\hline HITAssetCost (in millions, US \$) & $\begin{array}{l}\text { Health information technology asset } \\
\text { acquisition costs }\end{array}$ & 393 & $0.94(3.81 ; 0-29.8)$ \\
\hline TotAdmAndVsts (in thousands) & $\begin{array}{l}\text { Sum of inpatient admissions and } \\
\text { outpatient visits }\end{array}$ & 405 & $\begin{array}{l}303.62(276.89 ; 5.19- \\
1853.46)\end{array}$ \\
\hline Herfindahl-Hirschman Index & $\begin{array}{l}\text { Competition index }(1=\text { monopoly }) \\
\text { per hospital referral region }\end{array}$ & 405 & $0.13(0.09 ; 0.03-0.56)$ \\
\hline PercMdcdElig & Percentage Medicaid eligibility & 405 & $0.22(0.08 ; 0.07-0.5)$ \\
\hline СOTH & Teaching hospital & 405 & $0.09(0.29 ; 0-1)$ \\
\hline Own_FP & For-profit ownership & 405 & $0.12(0.32 ; 0-1)$ \\
\hline Own_NP & Not-for-profit ownership & 405 & $0.77(0.42 ; 0-1)$ \\
\hline Own_Gov & Government ownership & 405 & $0.11(0.31 ; 0-1)$ \\
\hline PercCapit & $\begin{array}{l}\text { Percentage of net patient revenue } \\
\text { capitated }\end{array}$ & 375 & $0.79(4.17 ; 0-53)$ \\
\hline PercRsk & $\begin{array}{l}\text { Percentage of net patient revenue } \\
\text { shared risk }\end{array}$ & 347 & $1.77(5.41 ; 0-42)$ \\
\hline Region_MW & Midwestern region & 405 & $0.31(0.46 ; 0-1)$ \\
\hline Region_S & Southern region & 405 & $0.37(0.48 ; 0-1)$ \\
\hline Region_W & Western region & 405 & $0.02(0.14 ; 0-1)$ \\
\hline Region_NE & Northeast region & 405 & $0.3(0.46 ; 0-1)$ \\
\hline CMI & Case Mix Index & 393 & $1.74(0.33 ; 0.93-2.93)$ \\
\hline Urban & 1 if urban location & 405 & $1(0)$ \\
\hline \multicolumn{4}{|l|}{ County-level variables } \\
\hline CntyHlthRank & $\begin{array}{l}\text { Normalized within state county } \\
\text { health rankings for health outcomes, } \\
1 \text { being best }\end{array}$ & 405 & $0.4(0.32 ; 0-1)$ \\
\hline CntyPercPop65 & $\begin{array}{l}\text { Percentage of population aged }>65 \\
\text { years }\end{array}$ & 405 & $0.15(0.03 ; 0.09-0.26)$ \\
\hline CntyPercBlack & Percentage of population Black & 405 & $15.04(11.97 ; 0.6-63.7)$ \\
\hline CntyPercNative & Percentage of population Native & 405 & $0.6(1.53 ; 0.1-17.5)$ \\
\hline CntyPercLatino & Percentage of population Latino & 405 & $12.89(11.89 ; 0.8-60.6)$ \\
\hline
\end{tabular}




\begin{tabular}{clll}
\hline Group and variable & Description & Value, N & Values, mean (SD; range) \\
\hline CntyPercDpPov & $\begin{array}{l}\text { Percentage of population in deep } \\
\text { poverty }\end{array}$ & 405 & $6.64(2.59 ; 2.2-16)$ \\
CntyPercDisabled & $\begin{array}{l}\text { Percentage of population disabled } \\
\text { CntyBBMaxUP }\end{array}$ & 405 & $10.01(3.05 ; 5.1-17.2)$ \\
CntyHsholdIntUse & $\begin{array}{l}\text { Maximum advertised broadband } \\
\text { upload speed }\end{array}$ & 405 & $26.68(32.56 ; 1.56-160.98)$ \\
CntyADI & $\begin{array}{l}\text { Percentage of households who re- } \\
\text { port using the internet }\end{array}$ & 405 & $0.87(0.04 ; 0.72-0.97)$ \\
& $\begin{array}{l}\text { Area Deprivation Index (10=most } \\
\text { deprived })\end{array}$ & 405 & $5.04(1.51 ; 1.53-8.4)$ \\
\hline
\end{tabular}

${ }^{\mathrm{a}}$ More details about the outcome variables are available in Multimedia Appendix 1. 
Table 2. Telehealth discontinuation sample descriptive statistics averaged for 2016-2018 (for 524 US hospitals that had telehealth for all 3 years or started to remove telehealth in 2017 or 2018).

\begin{tabular}{|c|c|c|c|}
\hline Group and variable & Description & Value, $\mathrm{N}$ & Values, mean (SD; range) \\
\hline \multicolumn{4}{|l|}{ Telehealth adoption and outcomes } \\
\hline Telehealth video-based consultation & $\begin{array}{l}\text { Whether a hospital adopted tele- } \\
\text { health in a given year }\end{array}$ & 1572 & $0.93(0.26 ; 0$ to 1$)$ \\
\hline EDVisits $^{\mathrm{a}}$ (in thousands) & $\begin{array}{l}\text { Number of emergency department } \\
\text { visits }\end{array}$ & 1572 & $61.16(49.82 ; 0$ to 617.78$)$ \\
\hline TotAmbVisits $^{\mathrm{a}}$ (in thousands) & $\begin{array}{l}\text { Total number of ambulatory visits } \\
\text { (minus emergency department vis- } \\
\text { its) }\end{array}$ & 1572 & $\begin{array}{l}263.74(413.69 ; 1.02 \text { to } \\
6497.28)\end{array}$ \\
\hline OutpatSerRev $^{\mathrm{a}}$ (in millions, US \$) & Outpatient services revenue & 1550 & $\begin{array}{l}247.07(476.36 ;-1443.98 \text { to } \\
6717.17)\end{array}$ \\
\hline TotFacExp ${ }^{\mathrm{a}}$ (in millions, US \$) & Total facility expenses & 1572 & $\begin{array}{l}440.55(565.66 ; 13.91 \text { to } \\
6004.75)\end{array}$ \\
\hline HospRev $^{\mathrm{a}}$ (in millions, US \$) & Total hospital revenue & 1550 & $\begin{array}{l}188.32(377.16 ; 0 \text { to } \\
7055.45)\end{array}$ \\
\hline \multicolumn{4}{|l|}{ Hospital-level variables } \\
\hline SystemOwned & System ownership & 1572 & $0.86(0.35 ; 0$ to 1$)$ \\
\hline WageIndx & $\begin{array}{l}\text { Index of hospital labor market } \\
\text { wages }\end{array}$ & 1550 & $0.98(0.14 ; 0.71$ to 1.44$)$ \\
\hline HITAssetCost (in millions, US \$) & $\begin{array}{l}\text { Health information technology asset } \\
\text { acquisition costs }\end{array}$ & 1550 & $2.97(12.94 ; 0$ to 175.42$)$ \\
\hline TotAdmAndVsts (in thousands) & $\begin{array}{l}\text { Sum of inpatient admissions and } \\
\text { outpatient visits }\end{array}$ & 1572 & $\begin{array}{l}407.36(493.07 ; 3.82 \text { to } \\
6989.63)\end{array}$ \\
\hline Herfindahl-Hirschman Index & $\begin{array}{l}\text { Competition index }(1=\text { monopoly }) \\
\text { per hospital referral region }\end{array}$ & 1572 & $0.15(0.12 ; 0.03$ to 0.96$)$ \\
\hline PercMdcdElig & Percentage Medicaid eligibility & 1572 & $0.21(0.07 ; 0.05$ to 0.5$)$ \\
\hline COTH & Teaching hospital & 1572 & $0.16(0.37 ; 0$ to 1$)$ \\
\hline Own_FP & For-profit ownership & 1572 & $0.11(0.31 ; 0$ to 1$)$ \\
\hline Own_NP & Not-for-profit ownership & 1572 & $0.8(0.40 ; 0$ to 1$)$ \\
\hline Own_Gov & Government ownership & 1572 & $0.09(0.29 ; 0$ to 1$)$ \\
\hline PercCapit & $\begin{array}{l}\text { Percentage of net patient revenue } \\
\text { capitated }\end{array}$ & 1476 & $0.53(2.62 ; 0$ to 40$)$ \\
\hline PercRsk & $\begin{array}{l}\text { Percentage of net patient revenue } \\
\text { shared risk }\end{array}$ & 1381 & $2.28(7.33 ; 0$ to 81$)$ \\
\hline Region_MW & Midwestern region & 1572 & $0.33(0.47 ; 0$ to 1$)$ \\
\hline Region_S & Southern region & 1572 & $0.42(0.49 ; 0$ to 1$)$ \\
\hline Region_W & Western region & 1572 & $0.03(0.17 ; 0$ to 1$)$ \\
\hline Region_NE & Northeast region & 1572 & $0.21(0.41 ; 0$ to 1$)$ \\
\hline CMI & Case Mix Index & 1550 & $1.68(0.26 ; 0.99$ to 2.68$)$ \\
\hline Urban & 1 if urban location & 1572 & $1(0 ; 1$ to 1$)$ \\
\hline \multicolumn{4}{|l|}{ County-level variables } \\
\hline CntyHlthRank & $\begin{array}{l}\text { Normalized within state county } \\
\text { health rankings for health outcomes, } \\
1 \text { being best }\end{array}$ & 1572 & $0.39(0.3 ; 0$ to 1$)$ \\
\hline CntyPercPop65 & $\begin{array}{l}\text { Percentage of population aged }>65 \\
\text { years }\end{array}$ & 1572 & $0.15(0.04 ; 0.09$ to 0.35$)$ \\
\hline CntyPercBlack & Percentage of population Black & 1572 & $14.19(12.71 ; 0.4$ to 69.1$)$ \\
\hline CntyPercNative & Percentage of population Native & 1572 & $0.64(2.38 ; 0.1$ to 38.4$)$ \\
\hline
\end{tabular}




\begin{tabular}{clll}
\hline Group and variable & Description & Value, N & Values, mean (SD; range) \\
\hline CntyPercLatino & $\begin{array}{l}\text { Percentage of population Latino } \\
\text { CntyPercDpPov }\end{array}$ & 1572 & $12.2(13.79 ; 0.5$ to 90.6$)$ \\
Cercentage of population in deep & 1572 & $6.6(2.59 ; 1.8$ to 19.9) \\
poverty & $\begin{array}{l}\text { Percentage of population disabled } \\
\text { CntyPercDisabled }\end{array}$ & 1572 & $10.2(2.92 ; 4.2$ to 20.7) \\
CntyHsholdIntUse & $\begin{array}{l}\text { Maximum advertised broadband } \\
\text { upload speed }\end{array}$ & 1572 & $22.02(26.32 ; 1.26$ to \\
CntyADI & $\begin{array}{l}\text { Percentage of households who re- } \\
\text { port using the internet }\end{array}$ & 1572 & $0.87(0.05 ; 0.6$ to 0.97$)$ \\
& $\begin{array}{l}\text { Area Deprivation Index (10=most } \\
\text { deprived) }\end{array}$ & 1572 & $5.31(1.35 ; 2.01$ to 8.93) \\
\hline
\end{tabular}

${ }^{\mathrm{a}}$ More details about the outcome variables are available in Multimedia Appendix 1.

\section{Statistical Analyses}

We applied difference-in-differences (DID) estimation with propensity score matching at the firm (hospital) unit of analysis to understand the effect of telehealth adoption and discontinuation by US hospitals during the 2016-2018 period. We conducted 2 primary analyses that exploited 2 quasi-natural experiments. The first DID analysis focused on telehealth adoption and evaluated impacts on performance for hospitals that went from no telehealth to offering telehealth during this period. The second DID analysis focused on telehealth discontinuation and evaluated impacts for hospitals that went from offering telehealth to discontinuing telehealth during this period. Control group selection and formation is discussed later in this section. This design followed other notable studies that assessed the impact of health information technology adoption and use on outcomes [28-31] as well as recommendations on effectively estimating causal effects by means of observational data [32,33]. This design is appropriate for estimating causal effects when pre- and posttreatment observational data are available, treatment and control groups with sufficiently balanced covariates and common trends before treatment can be established, and exogenous shocks can be assumed to be consistent between groups [34].

For the telehealth adoption analysis, treatment hospitals are those that first did not offer telehealth but then offered telehealth in a subsequent year. As we have 3 years of data that include the telehealth video visit (yes or no) question, we restricted our focus to video visits for chronic conditions or postsurgical follow-up as opposed to also including consideration of telehealth related to remote patient monitoring and mental health and addiction as separately measured in the AHA Annual Survey. For all US hospitals surveyed by the AHA for this quasi-natural experiment, treatment hospitals are those that (1) did not offer telehealth in 2016 but started in 2017 or 2018 (group 1, n=71) or (2) did not offer telehealth in 2016 or 2017 but then started offering it in 2018 (group 2, n=14). Control hospitals are those that did not offer telehealth in all 3 years $(n=50)$.

For the telehealth discontinuation analysis, treatment hospitals are those that offered telehealth but then discontinued it in a subsequent year. For this quasi-natural experiment, the treatment hospitals are those that (1) offered telehealth in 2016 but discontinued in 2017 or 2018 (group 1, n=12) or (2) offered telehealth in both 2016 and 2017 but discontinued in 2018 (group 2, $\mathrm{n}=80$ ). Control hospitals are those that offered telehealth in all 3 years $(n=432)$.

To balance the covariates between the treatment and control groups in each of these analyses, we applied propensity scoring and, subsequently, matching. Propensity scoring is applied by first determining the propensity of a hospital being in the treatment group, given observable covariates $[35,36]$. Then, to reduce selection bias, a matching technique is used to find control group participants (hospitals, in this case) that ultimately result in no observable significant covariate differences between treatment and control groups [35]. Similar to Oh et al [30] and Bao et al [29], we calculated propensity scores by means of logistic regression for each of the analyses (ie, for the adoption analysis and then again for the discontinuation analysis), as explained further in this section. Our covariates consisted of both hospital-level variables and county-level variables, with SEs clustered at the hospital level to account for repeated county-level observations for hospitals within the same county. The logistic regression analysis results for propensity scores are reported in Multimedia Appendix 1.

Using the scores that resulted from obtaining predicted values per hospital, we applied one-to-many matching using both the propensity score and covariates (a one-to-one matching procedure was also tested, as reported in Multimedia Appendix 1 , and the results were similar). Matched hospitals belonged to the same teaching, urban, and system status. In addition, we matched hospitals with similar sizes by restricting hospital size (total admissions plus visits) to a difference of no more than a factor of 1.5 and a difference in propensity scores of no more than 0.1 . Therefore, for each treatment hospital, we had a cluster of hospitals as the control. For telehealth adoption, the result was a treatment group consisting of 85 hospitals and a matched sample control group consisting of 85 hospital clusters, with an average size of 2 controls and a median size of 1 control in each hospital cluster. For telehealth discontinuation, the result was a treatment group consisting of 92 hospitals and a matched sample control group consisting of 92 hospital clusters, with an average size of 28 controls and a median size of 17 controls in each hospital cluster. We used averaged outcomes (ED visits, total ambulatory visits, outpatient services revenue, total facility expenses, and hospital revenue) for each observed control 
cluster. The matching for hospitals in group 1 was conducted based on the propensity score and covariates observed at year 2016, and the matching for group 2 was based on observations at year 2017. Comparison of covariates between the 2 groups resulted in no significant differences.

To obtain the propensity score, we conducted a logistic regression analysis using treatment group membership ( 1 for yes and 0 for no) as the dependent variable for the adoption analysis and then again for the discontinuation analysis. We applied a collection of hospital and county level characteristics as the independent variables for each analysis, with the same control variables being used in each propensity score model. Let $p_{i t}=P($ hospital $i$ in the treatment group $)$ with the following formula:

$$
\ln \left(p_{i t} / 1-p_{i t}\right)=\beta_{0}+\beta^{\prime}{ }_{1} X_{i t}
$$

$\beta_{0}$ is the constant and $X_{i t}$ represents factors that affect a hospital's decision of whether telehealth existed for the adoption analysis (1=hospital is in the treatment group and therefore adopted telehealth in 2017 or 2018) or was discontinued for the discontinuation analysis $(1=$ hospital is in the treatment group and therefore discontinued telehealth in 2017 or 2018). $\beta^{\prime}{ }_{1}$ is the coefficient vector.

Next, identification of the change in ED visits, total ambulatory visits, outpatient services revenue, total facility expenses, and hospital revenue after telehealth adoption and discontinuation was derived through the following DID model, applied once to the adoption analysis and once to the discontinuation analysis. Note that when conducting the analyses, we combined hospitals from group 1 and group 2 as the treatment group. $\beta_{0}$ is the constant, $\beta_{1}$ is the effect from the treatment group, $\beta_{2}$ represents posttreatment periods, and $\beta_{3}$ is the treatment effect (ie, the DID effect), which is the expected value difference in the time trend as well as the difference between treatment and control groups after treatment. We included hospital fixed effects $\left(\mu_{i}\right)$ to address any time-invariant hospital heterogeneity and time fixed effects to address time trends $\left(\vartheta_{t}\right)$. We performed an estimation using ordinary least squares [31]. The DID equation representing our model is as follows:

$$
Y_{i t}=\beta_{0}+\beta_{1} T_{i t}+\beta_{2} p_{i t}+\beta_{3}\left(T_{i t} \times p_{i t}\right)+\mu_{i}+\vartheta_{t}+\varepsilon_{i t}
$$

\section{Robustness}

Threats to validity could include endogeneity of telehealth adoption and decision-making around discontinuation, especially if our sample was subject to selection bias. We addressed this concern by also conducting Heckman analyses. Furthermore, nonrandom market changes, after treatment, may differentially affect outcomes [37]. For instance, perhaps broadband infrastructure or household use of the Internet expanded or contracted at different rates between the control and treatment groups in or after 2017 or 2018 . These threats were addressed with our propensity scoring and matching approach that included county-level maximum broadband speeds and household internet use as covariates in the logistic regression analysis, in addition to several other covariates considered when scoring and matching. For instance, we also included the ADI in our propensity score matching procedure to address regional economic states and, potentially, changes over time such as changes after treatment that are not fully addressed in a DID model. Overall, we included several hospital-level (eg, Case Mix Index, hospital size, and market competition) and county-level covariates (eg, maximum broadband speeds, household internet use, county health ranking, and ADI) to address a variety of potential threats to validity (eg, differences in broadband penetration affecting telehealth adoption or outcomes). Finally, we also tested whether outcomes change in the years after treatment to provide additional explanatory information.

\section{Results}

\section{Common Trends}

For testing common trends, we plotted the averages of ED visits, total ambulatory visits, outpatient services revenue, total facility expenses, and hospital revenue for each of the groups at points in time (years) relative to when telehealth was adopted (Figure 1) or discontinued (Figure 2). Note that throughout the paper, the numbers of visits are shown in thousands, whereas expenses and revenue are shown in millions (US \$).

To test the common trends assumption statistically, we also interacted pretreatment values with corresponding time dummies within the DID model (Figure 1). None of the coefficients were significant, suggesting that the trends are sufficiently common.

Again, to test the common trends assumption statistically, we also interacted pretreatment values with corresponding time dummies within the DID model (Figure 2). None of the coefficients were significant, suggesting that the trends are sufficiently common. 
Figure 1. Common trends per outcome per year relative to when telehealth was adopted. EDVisits: emergency department visits; HospRev: hospital revenue; OutpatSerRev: outpatient services revenue; TotAmbVisits: total ambulatory visits; TotFacExp: total facility expenses.

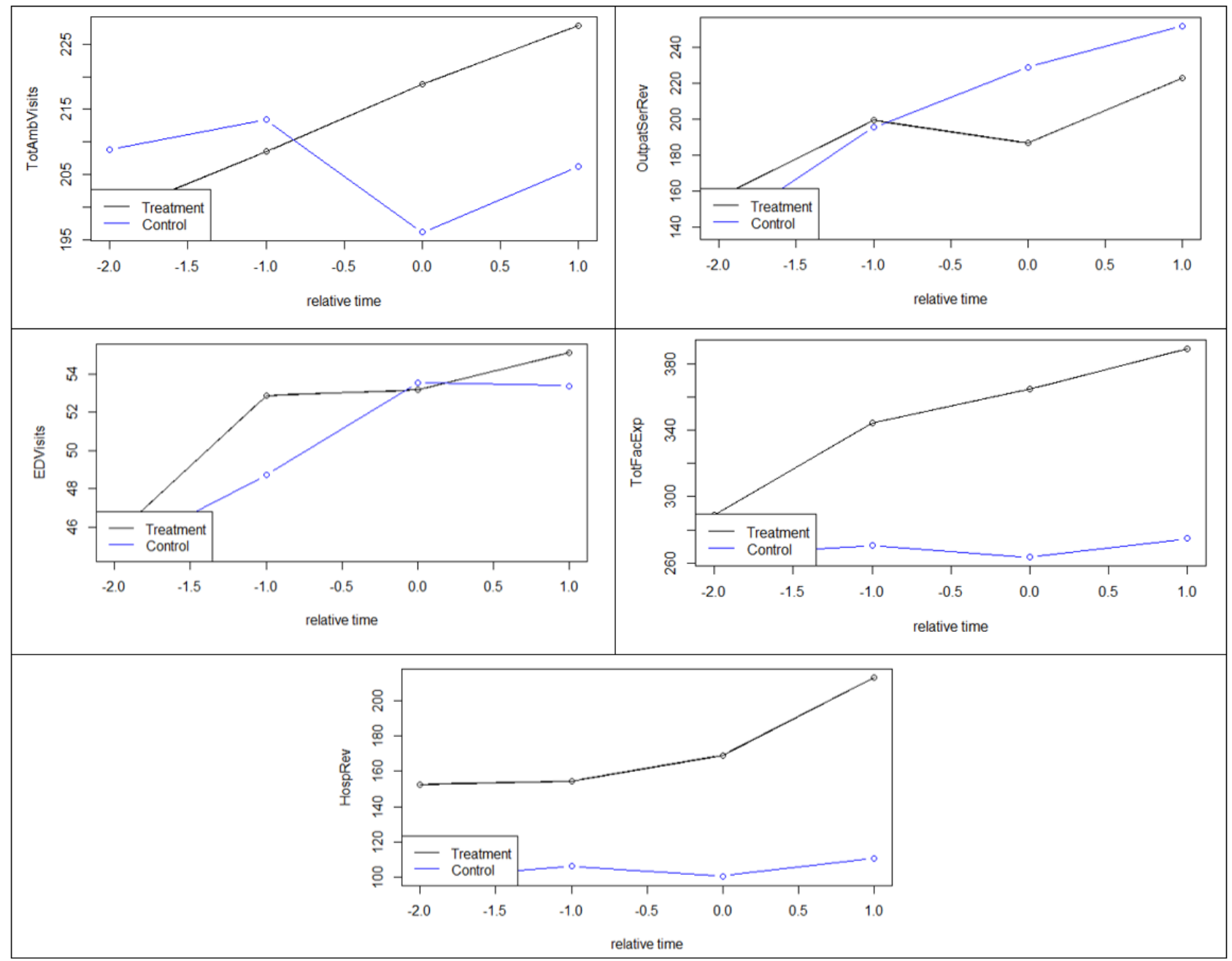


Figure 2. Common trends per outcome per year relative to when telehealth was discontinued. EDVisits: emergency department visits; HospRev: hospital revenue; OutpatSerRev: outpatient services revenue; TotAmbVisits: total ambulatory visits; TotFacExp: total facility expenses.

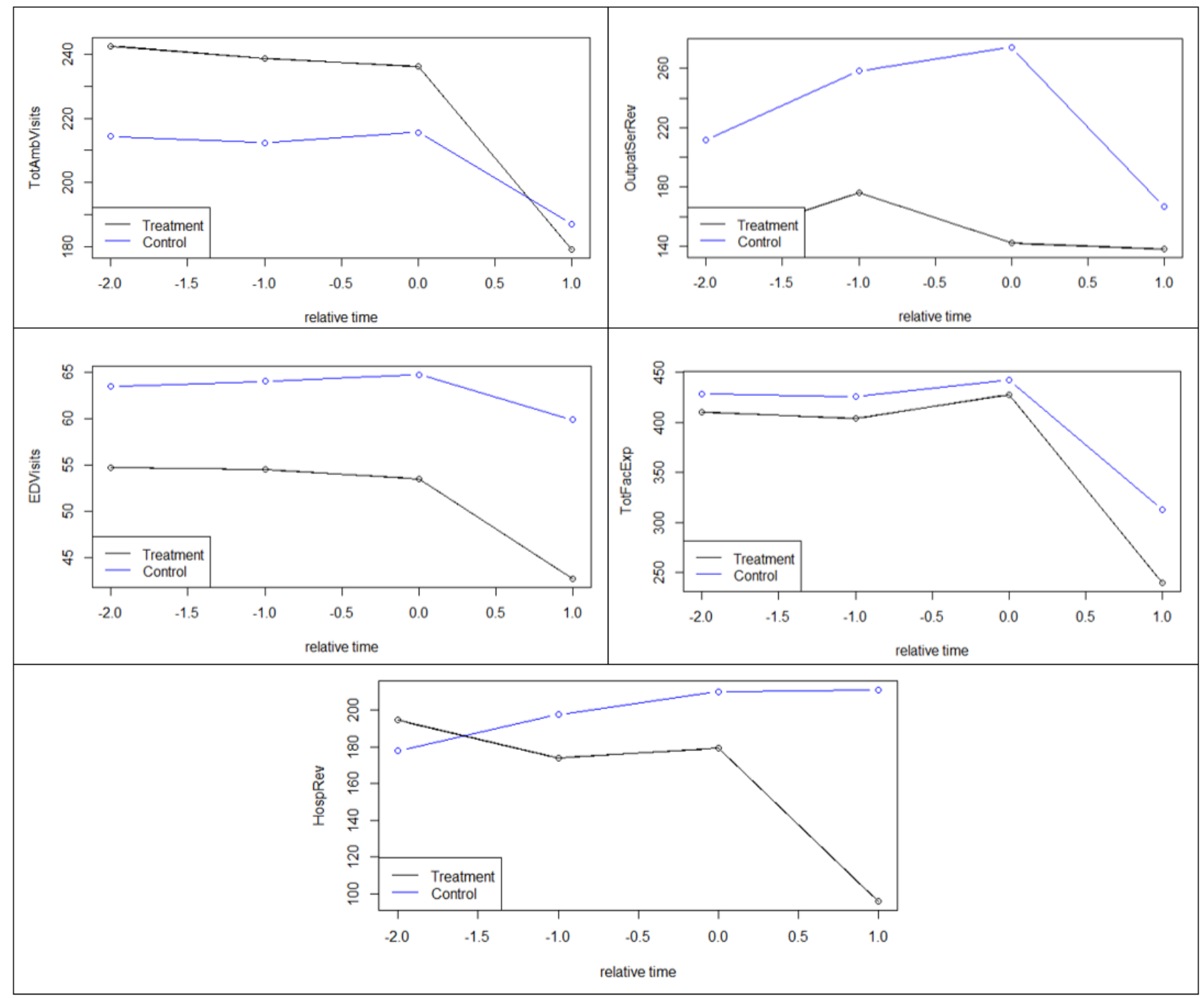

\section{Estimations}

The estimation results are reported below in Table 3 (for adoption) and Table 4 (for discontinuation; model analyses were conducted with $\mathrm{R}$ [The $\mathrm{R}$ Foundation for Statistical Computing]). For brevity, control variables are not included in the tables, but they were included in all regressions along with hospital and time fixed effects. The interaction terms represent the DID effect, which represents the expected value of the additional difference between the treatment and control groups after treatment (ie, the end of the time trend), when first accounting for the differences in time trends and difference in treatment and control groups.

For telehealth adoption, we found the DID interaction term for total ambulatory visits to be positive and significant $(P=.008)$. This means that the expected value of total ambulatory visits was higher in the treatment group than in the control group, even after accounting for the time and group differences, as well as several covariates discussed earlier and also in Multimedia Appendix 1. The average total ambulatory visits, as reported earlier, was 196 (thousand; SD 209 [thousand]). Given that the DID coefficient is 24.53 (thousand), this effect represents a significant increase in total ambulatory visits. Thus, we conclude that telehealth adoption resulted in more ambulatory visits for the adopting US hospitals during the period studied.

We further found the DID interaction term to be positive $(P<.001)$ for the effect on total facility expenses. Thus, the expected value of total facility expenses was higher in the treatment group (ie, those that adopted telehealth) than in the control group (ie, similar hospitals that did not have, and did not adopt, telehealth during the same period). The average total facility expenses in our sample, as reported earlier, was (in millions) US \$321.61 (SD US \$342.3). The coefficient (in millions) is US $\$ 33.39$ ( $P<.001)$, which represents a substantial average increase in the expenses when telehealth was adopted.

We also found the DID interaction term to be positive $(P=.004)$ for the effect on hospital revenue, which suggests higher total revenue on average for those in the treatment group. The average total hospital revenue in our sample, as reported earlier, was (in millions) US $\$ 152.34$. The coefficient (in millions) is $\$ 32.60$ $(P=.004)$, which represents a substantial average increase in the revenue when telehealth was adopted. However, we also note that this coefficient is slightly lower than that of the average 
increase in total facility expenses, suggesting that profits are likely to be negative or minimal when telehealth is first adopted.

The impact on ED visits $(P=.36)$ was nonsignificant. The impact on outpatient services revenue was marginally significant $(P=.01)$ and negative, suggesting that adoption led to at least a temporary drop in revenue, on average, in comparison with the control group.

For telehealth discontinuation, we found the DID interaction term (trtxpost) to be significant and negative $(P=.02)$ for the effect on outpatient services revenue. This means that the expected value for outpatient services revenue, ceteris paribus, was lower in the treatment group (ie, the group that discontinued telehealth) than in the control group, after accounting for the time trend and the assumed trend for the counterfactual. We also note that many control variables and fixed effects, to account for an unobserved time invariant heterogeneity, were accounted for. The average outpatient service revenue in our sample, as reported earlier, was (in millions) US \$247.07. The coefficient (millions) is -US $\$ 65.37(P=.02)$, which represents a substantial average drop in revenue compared with the control group when telehealth was discontinued.

We also found the DID interaction term to be negative and marginally significant $(P=.09)$ for the effect on hospital revenue. This again means that the expected value, given all the aforementioned trends and variables, was lower in the treatment group than in the control group after treatment. The average hospital revenue for our sample, as reported earlier, was (in millions) US \$188.32. Given that the coefficient (in millions) is -US $\$ 13.22$, this represents a substantial potential average drop in total hospital revenue when telehealth was discontinued.

The impacts on ED visits $(P=.10)$, total ambulatory visits $(P=.28)$, and total facility expenses $(P=.35)$ were nonsignificant.

Table 3. Difference-in-differences results for telehealth adoption.

\begin{tabular}{|c|c|c|c|c|c|c|c|c|c|c|}
\hline & $\begin{array}{l}\text { Emergency } \\
\text { department } \\
\text { visits (in } \\
\text { thousands) }\end{array}$ & $P$ value & $\begin{array}{l}\text { Total ambula- } \\
\text { tory visits } \\
\text { (in thou- }^{\text {sands) }}{ }^{\text {a }}\end{array}$ & $P$ value & $\begin{array}{l}\text { Outpatient ser- } \\
\text { vices revenue } \\
\text { (in millions, US } \\
\$)^{\mathrm{a}}\end{array}$ & $P$ value & $\begin{array}{l}\text { Total facility } \\
\text { expenses (in } \\
\text { millions, US } \\
\$)^{\mathrm{a}}\end{array}$ & $P$ value & $\begin{array}{l}\text { Hospital } \\
\text { revenue (in } \\
\text { millions, } \\
\text { US \$) }\end{array}$ & $P$ value \\
\hline $\operatorname{trt}^{\mathrm{b}}$ & $88.19\left(6.19^{c}\right)$ & $<.001$ & $\begin{array}{l}64.10 \\
(10.93)\end{array}$ & $<.001$ & $-159.01(19.86)$ & $<.001$ & $\begin{array}{l}360.58 \\
(5.49)\end{array}$ & $<.001$ & $\begin{array}{l}59.45 \\
(24.76)\end{array}$ & .02 \\
\hline post $^{\mathrm{d}}$ & $1.00(1.52)$ & .51 & $\begin{array}{l}-15.18 \\
(6.96)\end{array}$ & .03 & 29.85 (19.39) & .13 & $\begin{array}{l}-16.29 \\
(7.78)\end{array}$ & .04 & $\begin{array}{l}6.68 \\
(21.85)\end{array}$ & .77 \\
\hline $\operatorname{trt} \times$ post & $-1.49(1.63)$ & .36 & $24.53(9.15)$ & .008 & $-34.64(20.71)$ & .10 & $33.39(6.36)$ & $<.001$ & $\begin{array}{l}32.60 \\
(11.24)\end{array}$ & .004 \\
\hline $\begin{array}{l}\text { Hospital } \\
\text { fixed effects }\end{array}$ & $\checkmark$ & $\mathrm{N} / \mathrm{A}^{\mathrm{e}}$ & $\checkmark$ & N/A & $\checkmark$ & N/A & $\checkmark$ & N/A & $\checkmark$ & N/A \\
\hline $\begin{array}{l}\text { Time fixed } \\
\text { effects }\end{array}$ & $\checkmark$ & N/A & $\checkmark$ & N/A & $\checkmark$ & N/A & $\checkmark$ & N/A & $\checkmark$ & N/A \\
\hline (Intercept) & $29.94(2.63)$ & $<.001$ & $74.04(5.60)$ & $<.001$ & $153.46(16.46)$ & $<.001$ & $\begin{array}{l}108.13 \\
(3.80)\end{array}$ & $<.001$ & $\begin{array}{l}62.73 \\
(23.61)\end{array}$ & .008 \\
\hline $\mathrm{n}$ & $499^{f}$ & N/A & 510 & N/A & $502^{\mathrm{g}}$ & N/A & 510 & N/A & $502^{\mathrm{h}}$ & N/A \\
\hline$R^{2}$ & 0.96 & N/A & 0.97 & N/A & 0.90 & N/A & 0.99 & N/A & 0.95 & N/A \\
\hline$F$-statistic & 44.46 & $<.001$ & 53.56 & $<.001$ & 16.32 & $<.001$ & 313 & $<.001$ & 36.6 & $<.001$ \\
\hline
\end{tabular}

${ }^{\mathrm{a}} \mathrm{All}$ the dependent variables are Winsorized at 0.01 and 0.99 level.

$\mathrm{b}_{\text {trt: treatment group. }}$

${ }^{\mathrm{c}}$ Robust SEs clustered at the hospital level (in parentheses).

$\mathrm{d}_{\text {post: posttreatment time periods. }}$

${ }^{\mathrm{e}} \mathrm{N} / \mathrm{A}$ : not applicable.

${ }^{\mathrm{f}}$ A total of 11 observations that did not have a mention of an emergency department visit were omitted from the model for emergency department visits, which is why the $\mathrm{n}$ is 499 instead of 510 .

$\mathrm{g}_{\mathrm{A}}$ total of 8 observations that did not have a mention of outpatient services revenue were omitted from the model for outpatient services revenue, which is why the $\mathrm{n}$ is 502 instead of 510 .

${ }^{\mathrm{h}} \mathrm{A}$ total of 8 observations that did not have a mention of hospital revenue were omitted from the model for hospital revenue, which is why the $\mathrm{n}$ is 502 instead of 510 
Table 4. Difference-in-differences results for telehealth discontinuation.

\begin{tabular}{|c|c|c|c|c|c|c|c|c|c|c|}
\hline & $\begin{array}{l}\text { Emergency } \\
\text { department } \\
\text { visits (in } \\
\text { thousands) }\end{array}$ & $P$ value & $\begin{array}{l}\text { Total ambula- } \\
\text { tory visits } \\
\text { (in thou- } \\
\text { sands) }^{\mathrm{a}}\end{array}$ & $P$ value & $\begin{array}{l}\text { Outpatient ser- } \\
\text { vices revenue } \\
\text { (in millions, US } \\
\$)^{\mathrm{a}}\end{array}$ & $P$ value & $\begin{array}{l}\text { Total facility } \\
\text { expenses (in } \\
\text { millions, US } \\
\$)^{\mathrm{a}}\end{array}$ & $P$ value & $\begin{array}{l}\text { Hospital } \\
\text { revenue (in } \\
\text { millions, } \\
\text { US \$) }\end{array}$ & $P$ value \\
\hline $\operatorname{trt}^{\mathrm{b}}$ & $26.86\left(2.06^{\mathrm{c}}\right)$ & $<.001$ & $26.72(4.98)$ & $<.001$ & $170.08(37.33)$ & $<.001$ & $\begin{array}{l}58.12 \\
(12.30)\end{array}$ & $<.001$ & $\begin{array}{l}-104.41 \\
(18.51)\end{array}$ & $<.001$ \\
\hline $\operatorname{post}^{\mathrm{d}}$ & $-0.25(1.11)$ & .83 & $2.68(6.23)$ & .67 & $-10.91(29.27)$ & .71 & $0.07(5.06)$ & .99 & $\begin{array}{l}9.85 \\
(10.40)\end{array}$ & .34 \\
\hline $\operatorname{trt} \times$ post & $-1.65(1.01)$ & .11 & $-7.84(7.30)$ & .28 & $-65.37(26.76)$ & .02 & $7.15(7.65)$ & .35 & $\begin{array}{l}-13.22 \\
(7.70)\end{array}$ & .09 \\
\hline $\begin{array}{l}\text { Hospital } \\
\text { fixed effects }\end{array}$ & $\checkmark$ & $\mathrm{N} / \mathrm{A}^{\mathrm{e}}$ & $\checkmark$ & N/A & $\checkmark$ & N/A & $\checkmark$ & N/A & $\checkmark$ & N/A \\
\hline $\begin{array}{l}\text { Time fixed } \\
\text { effects }\end{array}$ & $\checkmark$ & N/A & $\checkmark$ & N/A & $\checkmark$ & N/A & $\checkmark$ & N/A & $\checkmark$ & N/A \\
\hline (Intercept) & $32.49(0.42)$ & $<.001$ & $29.91(2.74)$ & $<.001$ & $22.70(22.99)$ & .32 & $\begin{array}{l}123.88 \\
(8.24)\end{array}$ & $<.001$ & $\begin{array}{l}252.04 \\
(11.35)\end{array}$ & $<.001$ \\
\hline $\mathrm{n}$ & $551^{\mathrm{f}}$ & N/A & 552 & N/A & 552 & N/A & 552 & N/A & $549^{\mathrm{g}}$ & N/A \\
\hline$R^{2}$ & 0.98 & N/A & 0.99 & N/A & 0.76 & N/A & 0.99 & N/A & 0.98 & N/A \\
\hline$F$-statistic & 94.6 & $<.001$ & 154.3 & $<.001$ & 6.10 & $<.001$ & 517.5 & $<.001$ & 110.8 & $<.001$ \\
\hline
\end{tabular}

${ }^{\mathrm{a}}$ All the dependent variables are Winsorized at 0.01 and 0.99 level.

$\mathrm{b}_{\text {trt: treatment group. }}$

${ }^{\mathrm{c}}$ Robust SEs clustered at the hospital level (in parentheses).

${ }^{d}$ post: posttreatment time periods.

${ }^{\mathrm{e}} \mathrm{N} / \mathrm{A}$ : not applicable.

${ }^{\mathrm{f}}$ An observation that did not have a mention of an emergency department visit was omitted from the model for emergency department visits, which is why the $\mathrm{n}$ is 551 instead of 552 .

${ }^{\mathrm{g}} \mathrm{A}$ total of 3 observations that did not have a mention of hospital revenue were omitted from the model for hospital revenue, which is why the $\mathrm{n}$ is 549 instead of 552 .

\section{Robustness Checks}

We conducted additional tests to address potential endogeneity issues and threats to validity. First, hospital management, not some central regulatory authority, makes telehealth adoption and discontinuation decisions. Thus, our sample has a potential self-selection endogeneity issue. To address this statistically, beyond the use of propensity score matching, we used a Heckman model [38,39]. The Heckman model consists of 2 stages and is designed to control for those omitted from the sample. The first stage models the self-selection decision, that is, whether a hospital adopts or discontinues telehealth. The second stage models the treatment effect while taking into consideration the selection decision by including the inverse mills ratio calculated from the first stage. The results of this robustness check are available in Multimedia Appendix 1 and are consistent with our primary results.

To test whether the outcomes were different for different years after treatment, we conducted 2-sample $t$ tests using the 2018 data for group 1 ( 2 years after the treatment) versus the 2018 data of group 2 (1 year after the treatment). Recall that both group 1 and group 2 consist of treatment hospitals. Hospitals in group 1 are those that did not receive treatment in 2016, then received treatment in 2017 and 2018. Hospitals in group 2 are those that did not receive treatment in 2016 and 2017, then received treatment in 2018. The results are reported in Table 5 (for adoption) and Table 6 (for discontinuation).

We observed that after telehealth was adopted, there was an upward trend for the number of visits, expenses, and revenue when comparing year 2 to year 1 after the treatment (Table 5), although none are significant.

We observed that after telehealth was discontinued, there was no significant difference for most of the outcome variables, except for ED visits and total facility expenses (Table 6). For ED visits, we observed that the number of ED visits decreased further 2 years after the treatment compared with the previous year. The same trend of a further decrease 2 years after the treatment was found for total facility expenses. 
Table 5. Results of comparison of outcome variables after treatment (year 1 vs year 2) after telehealth was adopted.

\begin{tabular}{|c|c|c|c|c|c|}
\hline & $\begin{array}{l}\text { Emergency depart- } \\
\text { ment visits (in } \\
\text { thousands) }\end{array}$ & $\begin{array}{l}\text { Total ambulatory visits } \\
\text { (in thousands) }\end{array}$ & $\begin{array}{l}\text { Total facility } \\
\text { expenses (in } \\
\text { millions, US \$) }\end{array}$ & $\begin{array}{l}\text { Outpatient services revenue (in mil- } \\
\text { lions, US \$) }\end{array}$ & $\begin{array}{l}\text { Hospital revenue (in mil- } \\
\text { lions, US \$) }\end{array}$ \\
\hline $\begin{array}{l}\text { Year } 1, \mathrm{n}, \text { mean } \\
(\mathrm{SD}) ; \text { median }\end{array}$ & $\begin{array}{l}14,46.03(24.08) \\
44.61\end{array}$ & $\begin{array}{l}14,184.86(163.96) \\
161.47\end{array}$ & $\begin{array}{l}14,329.75 \\
(436.80) ; \\
193.85\end{array}$ & $14,196.18$ (88.89); 91.62 & $14,137.33$ (209.57); 42.19 \\
\hline $\begin{array}{l}\text { Year } 2, \mathrm{n}, \text { mean } \\
(\mathrm{SD}) ; \text { median }\end{array}$ & $\begin{array}{l}71,55.15(29.52) \\
47.47\end{array}$ & $\begin{array}{l}71,227.88(256.83) \\
138.87\end{array}$ & $\begin{array}{l}71,389.40 \\
(389.39) \\
323.32\end{array}$ & $71,222.58$ (407.19); 119.02 & $71,213.31$ (366.04); 96.29 \\
\hline $\begin{array}{l}t \text { test, difference } \\
\text { (SE) }\end{array}$ & $9.12(7.34)$ & $43.02(53.37)$ & $59.66(125.55)$ & $26.40(102.30)$ & $75.99(71.67)$ \\
\hline
\end{tabular}

Table 6. Results of comparison of outcome variables after treatment (year 1 vs year 2) after telehealth was discontinued.

\begin{tabular}{|c|c|c|c|c|c|}
\hline & $\begin{array}{l}\text { Emergency depart- } \\
\text { ment visits (in } \\
\text { thousands) }\end{array}$ & $\begin{array}{l}\text { Total ambulatory visits } \\
\text { (in thousands) }\end{array}$ & $\begin{array}{l}\text { Total facility } \\
\text { expenses (in } \\
\text { millions, US \$) }\end{array}$ & $\begin{array}{l}\text { Outpatient services revenue (in mil- } \\
\text { lions, US \$) }\end{array}$ & $\begin{array}{l}\text { Hospital revenue (in mil- } \\
\text { lions, US \$) }\end{array}$ \\
\hline $\begin{array}{l}\text { Year } 1, \mathrm{n} \text {, mean } \\
\text { (SD); median }\end{array}$ & $\begin{array}{l}80,55.01(35.37) \\
48.72\end{array}$ & $\begin{array}{l}80,243.16(341.72) \\
111.67\end{array}$ & $\begin{array}{l}80,456.60 \\
(589.83) \\
247.90\end{array}$ & $80,172.74$ (224.79); 91.62 & $80,193.38(333.23) ; 77.20$ \\
\hline $\begin{array}{l}\text { Year 2, n, mean } \\
\text { (SD); median }\end{array}$ & $\begin{array}{l}12,42.72(18.65) \\
39.10\end{array}$ & $\begin{array}{l}12,179.07(134.64) ; \\
134.65\end{array}$ & $\begin{array}{l}12,239.61 \\
(155.71) \\
199.68\end{array}$ & $12,150.55(103.77) ; 162.36$ & $12,95.81(78.31) ; 75.31$ \\
\hline $\begin{array}{l}t \text { test, difference } \\
\text { (SE), } P \text { value }\end{array}$ & $-12.29(6.68), .03$ & $-64.09(54.61), .12$ & $\begin{array}{l}-216.98 \\
(79.80), .003\end{array}$ & $-22.19(38.47), .28$ & -97.57 (43.58), .01 \\
\hline
\end{tabular}

\section{Discussion}

\section{Overview}

This study assessed the impact of telehealth video visit consultation adoption or discontinuation by US hospitals from 2016 to 2018 through analysis of 2 quasi-natural experiments (ie, one for adoption and one for discontinuation). After conducting a number of robustness checks to validate our findings, we can conclude that, for this period, telehealth adoption resulted in an average increase in total ambulatory visits, total facility expenses, and hospital revenue in comparison with the control group of similar hospitals that neither offered, nor had adopted, telehealth services during this same period. Telehealth discontinuation resulted in an average reduction in outpatient services revenue compared with the control group of similar hospitals that did not discontinue telehealth during this period. Furthermore, in our robustness check, we found telehealth discontinuation to reduce total facility expenses over time, suggesting that telehealth investments are costly and cannot simply rely on existing communications infrastructure (ie, it is not the case that little to no additional costs are involved).

\section{Principal Findings}

First, we found that telehealth adoption for US hospitals from 2016 to 2018 resulted in increased visits, expenses, and revenue in comparison with the control group. These findings are similar to those of another study that found telehealth not only increased use (ie, resulted in more visits), but also increased costs [3]. However, this previous study focused on direct-to-consumer telehealth for a payer-based patient population in California as opposed to telehealth offered by hospitals throughout the United States. Thus, we contribute by demonstrating a similar trend at the national level and for hospital-based (provider-based) telehealth as opposed to payer-supported direct-to-consumer telehealth. The implications of our findings are that providers switching from not offering telehealth to offering telehealth can expect higher visit volumes but not necessarily significant increases in profits, especially given that the coefficient for increased expenses (US \$33.39 million) is slightly higher than the coefficient for increased revenue (US \$32.60 million) in our telehealth adoption results. The results make sense because it has been found that offering telehealth can increase provider workload [40], reduce workflow efficiency (at first) [23,41], and result in billing and payment issues [42]. Furthermore, given that payment parity laws are only now becoming more commonplace for telehealth and are still subject to significant variability [43], revenue from additional telehealth visits may be less than expected, especially if visits that were typically in person are now being replaced with video-based visits. Thus, telehealth adoption may provide more convenience for patients but may have mixed impacts on provider performance, likely requiring a significant investment by providers in overcoming barriers at least in the short term, as was also found in other telehealth studies such as those in the area of telestroke [44].

Second, we found that telehealth discontinuation had a negative impact on outpatient services revenue. The implication is that once telehealth is offered, performance may subsequently suffer if it is discontinued. Thus, careful thought must be given to what might happen with patient expectations once telehealth is offered, even if only for a short time. However, we also note that, although the observed decline in visit volume might be 
expected to be responsible for loss in revenue, we did not find a significant impact on total ambulatory visits in comparison with the control group when telehealth was discontinued. This means that the revenue loss may be attributable to a decline in other outpatient services such as wellness and prevention programs, observation programs, supplies, laboratory tests, or other services, which suggests a spillover effect. Future research could examine this effect in more detail to gain a deeper understanding of potential spillover effects between discontinuing a digital service and other outpatient services offered. Most importantly, spillover effects aside, our results demonstrate that offering a digital service may change expectations, which cannot simply be reverted if telehealth is then no longer offered in a future period.

\section{Limitations}

We note that this study is limited by the binary nature of the response variable in that telehealth is a yes or no variable rather than an extent of use or assimilation variable. We also note that our data dates to before the COVID-19 pandemic period in which telehealth adoption and use significantly increased at first but subsequently significantly declined [8,45]. Future research could consider whether the effects found in this study are consistent with the postpandemic period, once more data are available. This study is also limited by a lack of detail in regard to the mechanisms that cause the effects we observed. This is also a significant opportunity for future research. Finally, our data are limited to the United States.

\section{Additional Thoughts on Future Research}

In addition to studying the spillover effects of telehealth adoption and discontinuation decisions, as well as determination of whether the effects found here remain consistent after the pandemic once more data are available, future research could consider price optimization for service channel differences such as in-person versus video visits and establish recommendations for optimal mixes of visit types, conditional on patient conditions and provider expertise. Given that the relationship among telehealth use, costs, and revenue is complex, uncertain, and mixed, more research is needed on service mix optimization.

We further note that our results are specific to US hospitals. Future research could consider whether these results are consistent with telehealth being adopted and discontinued in other countries and regions, as well as any unique conditions that may affect telehealth differently in other areas.

Finally, telehealth impacts, especially from adoption of telehealth, are likely to change over time. For instance, costs associated with telehealth may decrease in some ways as efficiencies are gained over time but increase in other ways such as potentially more technical and scheduling staff being required to support a mix of in-person and telehealth visits. Therefore, an excellent future area for future research will be a more fine-grained analysis of telehealth-specific costs over a longer period of time.

\section{Conclusions}

In conclusion, this study offers insights into the effects of telehealth adoption and discontinuation by US hospitals from 2016 to 2018. It is our hope that these results will inform health care providers, administrators, and policy makers regarding expected performance outcomes when telehealth adoption and discontinuation decisions are made.

\section{Conflicts of Interest}

None declared.

\section{Multimedia Appendix 1}

Additional descriptions, first stage results, and robustness checks.

[DOCX File, 49 KB-Multimedia Appendix 1]

\section{References}

1. Tuckson RV, Edmunds M, Hodgkins ML. Telehealth. N Engl J Med 2017 Oct 19;377(16):1585-1592. [doi: 10.1056/nejmsr1503323]

2. Shigekawa E, Fix M, Corbett G, Roby DH, Coffman J. The current state of telehealth evidence: a rapid review. Health Aff (Millwood) 2018 Dec;37(12):1975-1982. [doi: 10.1377/hlthaff.2018.05132] [Medline: 30633674]

3. Ashwood JS, Mehrotra A, Cowling D, Uscher-Pines L. Direct-to-consumer telehealth may increase access to care but does not decrease spending. Health Aff (Millwood) 2017 Mar 01;36(3):485-491. [doi: 10.1377/hlthaff.2016.1130] [Medline: 28264950]

4. Slightam C, Gregory AJ, Hu J, Jacobs J, Gurmessa T, Kimerling R, et al. Patient perceptions of video visits using veterans affairs telehealth tablets: survey study. J Med Internet Res 2020 Apr 15;22(4):e15682 [FREE Full text] [doi: 10.2196/15682] [Medline: 32293573]

5. Liu N, Huang R, Baldacchino T, Sud A, Sud K, Khadra M, et al. Telehealth for noncritical patients with chronic diseases during the COVID-19 pandemic. J Med Internet Res 2020 Aug 07;22(8):e19493 [FREE Full text] [doi: 10.2196/19493] [Medline: $\underline{\text { 32721925] }}$

6. Kalankesh L, Pourasghar F, Nicholson L, Ahmadi S, Hosseini M. Effect of telehealth interventions on hospitalization indicators: a systematic review. Perspect Health Inf Manag 2016;13(Fall):1h [FREE Full text] [Medline: 27843425] 
7. Kruse CS, Krowski N, Rodriguez B, Tran L, Vela J, Brooks M. Telehealth and patient satisfaction: a systematic review and narrative analysis. BMJ Open 2017 Aug 03;7(8):e016242 [FREE Full text] [doi: 10.1136/bmjopen-2017-016242] [Medline: 28775188]

8. Monaghesh E, Hajizadeh A. The role of telehealth during COVID-19 outbreak: a systematic review based on current evidence. BMC Public Health 2020 Aug 01;20(1):1193 [FREE Full text] [doi: 10.1186/s12889-020-09301-4] [Medline: 32738884]

9. Totten AM, Womack DM, Eden KB, McDonagh MS, Griffin JC, Grusing S, et al. Telehealth: Mapping the Evidence for Patient Outcomes From Systematic Reviews. Rockville, MD: Agency for Healthcare Research and Quality (US); 2016.

10. Wade VA, Karnon J, Elshaug AG, Hiller JE. A systematic review of economic analyses of telehealth services using real time video communication. BMC Health Serv Res 2010 Aug 10;10(1):233 [FREE Full text] [doi: 10.1186/1472-6963-10-233] [Medline: 20696073]

11. Adler-Milstein J, Kvedar J, Bates DW. Telehealth among US hospitals: several factors, including state reimbursement and licensure policies, influence adoption. Health Aff (Millwood) 2014 Mar;33(2):207-215. [doi: 10.1377/hlthaff.2013.1054] [Medline: 24493762]

12. Hwa K, Wren SM. Telehealth follow-up in lieu of postoperative clinic visit for ambulatory surgery: results of a pilot program. JAMA Surg 2013 Sep 01;148(9):823-827. [doi: 10.1001/jamasurg.2013.2672] [Medline: 23842982]

13. Lonergan PE, Washington Iii SL, Branagan L, Gleason N, Pruthi RS, Carroll PR, et al. Rapid utilization of telehealth in a comprehensive cancer center as a response to COVID-19: cross-sectional analysis. J Med Internet Res 2020 Jul 06;22(7):e19322 [FREE Full text] [doi: 10.2196/19322] [Medline: 32568721]

14. Woods LW, Snow SW. The impact of telehealth monitoring on acute care hospitalization rates and emergency department visit rates for patients using home health skilled nursing care. Home Healthc Nurse 2013 Jan;31(1):39-45. [doi: 10.1097/NHH.0b013e3182778dd3] [Medline: 23238623]

15. Schoenfeld AJ, Davies JM, Marafino BJ, Dean M, DeJong C, Bardach NS, et al. Variation in quality of urgent health care provided during commercial virtual visits. JAMA Intern Med 2016 May 01;176(5):635-642 [FREE Full text] [doi: 10.1001/jamainternmed.2015.8248] [Medline: 27042813]

16. Steventon A, Bardsley M, Billings J, Dixon J, Doll H, Hirani S, Whole System Demonstrator Evaluation Team. Effect of telehealth on use of secondary care and mortality: findings from the Whole System Demonstrator cluster randomised trial. BMJ 2012 Jun 21;344(jun21 3):e3874 [FREE Full text] [doi: 10.1136/bmj.e3874] [Medline: 22723612]

17. Ellimoottil C, An L, Moyer M, Sossong S, Hollander JE. Challenges and opportunities faced by large health systems implementing telehealth. Health Aff (Millwood) 2018 Dec;37(12):1955-1959. [doi: 10.1377/hlthaff.2018.05099] [Medline: 30633667]

18. Croymans D, Hurst I, Han M. Telehealth: the right care, at the right time, via the right medium. NEJM Catalyst Innov Care Delivery 2020;1(6):1-12 [FREE Full text]

19. Cho S, Mathiassen L, Gallivan M. Crossing the diffusion chasm: from invention to penetration of a telehealth innovation. Info Technol People 2009 Nov 13;22(4):351-366. [doi: 10.1108/09593840911002450]

20. Langabeer JR, Champagne-Langabeer T, Alqusairi D, Kim J, Jackson A, Persse D, et al. Cost-benefit analysis of telehealth in pre-hospital care. J Telemed Telecare 2016 Dec 05;23(8):747-751. [doi: 10.1177/1357633x16680541]

21. Hill RD, Luptak MK, Rupper RW, Bair B, Peterson C, Dailey N, et al. Review of veterans health administration telemedicine interventions. Am J Manag Care 2010 Dec;16(12 Suppl HIT):e302-e310. [Medline: 21322300]

22. Wosik J, Fudim M, Cameron B, Gellad Z, Cho A, Phinney D, et al. Telehealth transformation: COVID-19 and the rise of virtual care. J Am Med Inform Assoc 2020 Jun 01;27(6):957-962 [FREE Full text] [doi: 10.1093/jamia/ocaa067] [Medline: $\underline{32311034]}$

23. Lin CC, Dievler A, Robbins C, Sripipatana A, Quinn M, Nair S. Telehealth in health centers: key adoption factors, barriers, and opportunities. Health Aff (Millwood) 2018 Dec;37(12):1967-1974. [doi: 10.1377/hlthaff.2018.05125] [Medline: $\underline{30633683}$ ]

24. Baird A, Furukawa MF, Raghu TS. Understanding contingencies associated with the early adoption of customer-facing web portals. J Manag Inf Syst 2014 Dec 08;29(2):293-324. [doi: 10.2753/mis0742-1222290210]

25. Atasoy H, Chen P, Ganju K. The spillover effects of health IT investments on regional healthcare costs. Manag Sci 2018 Jun;64(6):2515-2534. [doi: 10.1287/mnsc.2017.2750]

26. Adler-Milstein J, Everson J, Lee SD. EHR adoption and hospital performance: time-related effects. Health Serv Res 2015 Dec;50(6):1751-1771 [FREE Full text] [doi: 10.1111/1475-6773.12406] [Medline: 26473506]

27. McCullough J, Parente S, Town R. Health information technology and patient outcomes: the role of organizational and informational complementarities. National Bureau of Economic Research. URL: https://www.nber.org/system/files/ working papers/w18684/w18684.pdf [accessed 2022-01-31]

28. Atasoy H, Greenwood BN, McCullough JS. The digitization of patient care: a review of the effects of electronic health records on health care quality and utilization. Annu Rev Public Health 2019 Apr 01;40:487-500. [doi: 10.1146/annurev-publhealth-040218-044206] [Medline: 30566385]

29. Bao C, Bardhan IR, Singh H, Meyer BA, Kirksey K. Patient-provider engagement and its impact on health outcomes: a longitudinal study of patient portal use. MISQ 2020 Jun 1;44(2):699-723. [doi: 10.25300/misq/2020/14180] 
30. Oh JC, Zheng ZE, Bardhan IR. Sooner or later? Health information technology, length of stay, and readmission risk. Prod Oper Manag 2017 Aug 03;27(11):2038-2053. [doi: 10.1111/poms.12748]

31. Ganju KK, Atasoy H, McCullough J, Greenwood B. The role of decision support systems in attenuating racial biases in healthcare delivery. Manag Sci 2020 Nov;66(11):5171-5181. [doi: 10.1287/mnsc.2020.3698]

32. Basu S, Meghani A, Siddiqi A. Evaluating the health impact of large-scale public policy changes: classical and novel approaches. Annu Rev Public Health 2017 Mar 20;38:351-370 [FREE Full text] [doi:

10.1146/annurev-publhealth-031816-044208] [Medline: 28384086]

33. Imbens GW, Wooldridge JM. Recent developments in the econometrics of program evaluation. J Economic Literature 2009 Mar 01;47(1):5-86. [doi: 10.1257/jel.47.1.5]

34. Wing C, Simon K, Bello-Gomez RA. Designing difference in difference studies: best practices for public health policy research. Annu Rev Public Health 2018 Apr 01;39:453-469. [doi: 10.1146/annurev-publhealth-040617-013507] [Medline: 29328877]

35. Guo S, Fraser MW. Propensity Score Analysis: Statistical Methods and Applications. Thousand Oaks, CA: SAGE Publications; 2014.

36. Caliendo M, Kopeinig S. Some practical guidance for the implementation of propensity score matching. J Economic Surveys 2008 Feb;22(1):31-72. [doi: 10.1111/j.1467-6419.2007.00527.x]

37. Kahn-Lang A, Lang K. The promise and pitfalls of differences-in-differences: reflections on 16 and pregnant and other applications. J Business Econ Stat 2019 Apr 02;38(3):613-620. [doi: 10.1080/07350015.2018.1546591]

38. Heckman JJ. Sample selection bias as a specification error. Econometrica 1979 Jan;47(1):153. [doi: 10.2307/1912352]

39. Certo ST, Busenbark JR, Woo H, Semadeni M. Sample selection bias and Heckman models in strategic management research. Strat Manag J 2016 Feb 09;37(13):2639-2657. [doi: 10.1002/smj.2475]

40. Sharma U, Clarke M. Nurses' and community support workers' experience of telehealth: a longitudinal case study. BMC Health Serv Res 2014 Apr 10;14(1):164 [FREE Full text] [doi: 10.1186/1472-6963-14-164] [Medline: 24721599]

41. Zulman DM, Wong EP, Slightam C, Gregory A, Jacobs JC, Kimerling R, et al. Making connections: nationwide implementation of video telehealth tablets to address access barriers in veterans. JAMIA Open 2019 Oct;2(3):323-329 [FREE Full text] [doi: 10.1093/jamiaopen/ooz024] [Medline: 32766533]

42. Sisk B, Alexander J, Bodnar C, Curfman A, Garber K, McSwain SD, et al. Pediatrician attitudes toward and experiences with telehealth use: results from a national survey. Acad Pediatr 2020 Jul;20(5):628-635 [FREE Full text] [doi:

10.1016/j.acap.2020.05.004] [Medline: 32437881]

43. Shachar C, Engel J, Elwyn G. Implications for telehealth in a postpandemic future: regulatory and privacy issues. JAMA 2020 Jun 16;323(23):2375-2376. [doi: 10.1001/jama.2020.7943] [Medline: 32421170]

44. Singh R, Baird A, Mathiassen L. Collaboration risk management in IT-enabled asymmetric partnerships: evidence from telestroke networks. Inf Organization 2018 Dec;28(4):170-191. [doi: 10.1016/j.infoandorg.2018.10.001]

45. Early impact of CMS expansion of medicare telehealth during COVID-19. Health Affairs Forefront. URL: https://www. healthaffairs.org/do/10.1377/forefront.20200715.454789/full/ [accessed 2022-01-31]

\section{Abbreviations}

ADI: Area Deprivation Index

AHA: American Hospital Association

DID: difference-in-differences

ED: emergency department

HCRIS: Healthcare Cost Report Information System

Edited by A Mavragani; submitted 20.03.21; peer-reviewed by E Jussupow, I Mircheva, M Rusll, M Jones; comments to author
24.06.21; revised version received 10.08.21; accepted 04.01.22; published 18.02.22
Please cite as:
Baird A, Cheng Y, Xia Y
Telehealth Adoption and Discontinuation by US Hospitals: Results From 2 Quasi-Natural Experiments
JMIR Form Res 2022;6(2):e28979
URL: $\underline{\text { https://formative.jmir.org/2022/2/e28979 }}$
doi: $\underline{10.2196 / 28979}$
PMID:

(CAaron Baird, Yichen Cheng, Yusen Xia. Originally published in JMIR Formative Research (https://formative.jmir.org), 18.02.2022. This is an open-access article distributed under the terms of the Creative Commons Attribution License 
(https://creativecommons.org/licenses/by/4.0/), which permits unrestricted use, distribution, and reproduction in any medium, provided the original work, first published in JMIR Formative Research, is properly cited. The complete bibliographic information, a link to the original publication on https://formative.jmir.org, as well as this copyright and license information must be included. 